be very unusual. Separation of the pubic bones without fracture at the patient's age, sixty-nine, must be rare. I think I may take it that the patient had total suppression of urine. But the usual symptoms were absent. Absence of peritonitis in such a case must be unusual. Whether the shock, combined with the injury to one kidney and suprarenal body, be sufficient to account for total suppression of urine, I must leave for abler pathologists to determine. I should state that the right kidney, in addition to the injuries, contained on its lower aspect an ancient cyst lined with an old inflammatory membrane, of about the capacity of a middle-sized walnut.

Stratford-on-Avon.

\section{A SUCCESSFUL CASE OF}

\section{NEPHROTOMY AND NEPHRECTOMY FOR SCROFULOUS PYELITIS.}

By GEORGE ELDER, M.D., SURGEON TO THE HOSPYTAL FOR WOMEN, NOTTINGHAM.

MRS. W-, aged thirty-six years, was admitted into the hospital under my care on April 29th, 1882, with a large fluctuating abdominal tumour. There was no family history of phthisis, and the patient, who was a multipara, had enjoyed fairly good health till two years and a half back, when she first experienced severe pains down the left side and leg, aggravated by exertion and accompanied with pain. ful micturition of scanty and turbid urine. At no time was there hæmaturia. To these symptoms were superadded rigors, fever, night sweats, occasional sickness, anorexia and progressive emaciation, and loss of strength. Latterly she had a troublesome cough with purulent expectoration and dyspnoea. On admission the urine was strongly ammoniacal, muco-purulent, and containing triple phosphates in abundance. The amount passed was small ; not more than sixteen ounces in twenty-four hours. Lithia water ad lib. speedily increased the flow. During the first few days, owing to the exhaustion induced by the journey from her home, a considerable distance, to Nottingham, and the extreme tenderness of the abdominal superficies, I confined myself to treatment of a sedative and restorative character. Her condition having somewhat improved, on May 10th, whilst under the influence of an anæe, thetic, I examined the swelling, with the result of finding dulness to extend from the anterior superior iliac spine up to and continuous with the cardiac area, and in the transverse direction from an inch to the left of the umbilicus round to the spinal column. The tumour was most prominent in front, and the wave of fluctuation was so distinct that it gave me the impression of the kidney having been converted into one large abscess. A chest examination revezled distinct evidence of tuberculous disease, particularly in the right apex.

The nature of the case having been pretty clearly made out, nephrotomy was performed by the usual lumbar incision. A large quantity of curdy pus was given vent to from two large abscess sacs, into which the kiduey had been converted, a friable partition dividinu them, which in the course of the operation I broke down with my fingers. A considerable quautity of similar tissue was removed in the same manner. The kidney was found to reach down to below the level of the iliac crest, and its adhesions to surrounding tissues were firm and extensive. Its interior bled freely, which, after washing out with carbolised water ( 1 in 80), I controlled by plugs of lint saturated with carbolised oil. The usual antiseptic precautions were observed during the operation. There was little sheck, and on the evening of the operation it was noted that the patient was quite free from pain and that the temperature had fallen one degree. For some few days the urine was freer from pus than formerly, and the general condition of the patient was somewhat im. proved. The wound discharged freely. For over three weeks matters were pretty much as above. The urine was never free from pus. The temperature fluctuated between $99^{\circ}$ and $103^{\circ}$; and night sweats only ceased when pilocarpine was administered. It is an interesting fact in the case that the temperature in both axillæ was never the same; usually higher on the right; the variation occasionally amounting to nearly two degrees. The sweating was most marked on the right side of the body; both symptoms pointing to morbid innervation of the cervical sympathetic. An attack of septic pleuro-pneumonia of the right base, which all but ended the record of the case, coupled with the want of benefit following the nephrotomy, strengthened my resolve to extirpate the kidney as soon as the patient's condition warranted it. This I did on June 20th by enlarging the former incision and supplementing it by a crucial. There was very great difficulty in enucleating the kidney from its capsule, mostly experienced at the point of insertion of the vessels. The friability of its structure also contributed to this, and at the same time gave rise to copious bleeding, which pressure by means of sponges checked. I tied the bloodvessels and ureter en masse with strong carbolised Chinese silk, and then cut away the kidney. Under the strain of the ligature, the friable tissue of which the pedicle was composed gave way, and for a time the hæmorrhage was appalling. A second and then a third were applied higher up, with the effect of stopping all bleeding, except from a few small arteries which were separately ligated. A few loosely applied metallic sutures, simply used to approximate the edges of the wound, after it had been washed out with carbolised water and tamponed, finished a very tedious operation. 'Through failure of the spray producer it was not done antiseptically.

The shock after the operation was extreme, so much so that for several hours it was doubtful whether the patient would rally. Frequently-repeated rectal injections of pancreatised beef-tea, and brandy, stood her in good stead. For the first forty-eight hours the scantiness of the renal secretion assisted in making the outlook more gloomy, but at the end of this time the quantity became natural in amount. After the operation its quality became normal, and has remained so ever since. With the above exceptions the patient made an uninterruptedly good recovery, and when she was discharged from hospital on account of the annual cleaning she had got quite plump, and there remained of the wound only a small sore.

Renunuts. - This was a very unpromising case upon which to perform such a grave operation, not only on account of the prostration induced by the condition for which relief was sought, but also because of the state of the chest and the drinking habits of the patient. I regret that the major operation was not at first performed, as by it time would have been saved and the intercurrent attack of pleuropneumonia averted. The variations in temperature before alluded to ceased with the nophrectomy, as also the hemihyperidrosis, and before her discharge there was an improvement in the chest symptoms.

Nottincham

\section{ON FATTY EMBOLA OCCURRING AFTER FRACTURES.}

BY R. SCOT SKIRVING, M.B.

LATE RESIDENT SURGEON TO THE ROYAL INFIRMARY, EDINBURGH.

THE following case, which I venture to think worthy of record, occurred last winter under the care of the late Professor Spence.

The patient, a temperate and healthy man of forty, was admitted into the Edinburgh Royal Infirmary on Feb. 18th, suffering from a compound fracture of both bones of the leg. The external opening was a very small one; indeed the injury was the minimum of a compound fracture. The wound was dressed antiseptically, and the leg laid on a wire splint. At night, as there was considerable oozing, the wound was again dressed and a compress applied. The next day, after an easy night, the pad was removed and the leg again dressed. In the afternoon of the same day, the patient, having been in conversation with a man in the next bed, ceased to speak; he was supposed to have fallen asleep, but it was soon noticed that something was amiss. His condition then was as follows:-Pulse 130 per minute, full and soft; respiration 24 per minute, regular, and not stertorous ; temperature $100^{\circ} \mathrm{F}$. On auscultation, a few crepitations might be heard at the bases of the lungs. The face was somewhat dusky ; lips pale; pupils contracted, and sluggish in response to light. He was unconscioue, and peripheral stimulation was but slowly responded to. The patient yawned at intervals. During the night the respiration was 